\title{
Les pâturages artificiels en zone de savane à saison sèche marquée
}

\author{
par M. MOSNIER
}

\begin{abstract}
RÉSUMÉ
Après un bref résumé des conditions climatiques de la République du Tchad, les auteurs exposent les résultats oblenus dans l'introduction de plantes fourrogères.

Le cactus inerme donne des résultats décevaris; par contre les cultures de Panicum antidotale, Andropogon gayanus, Stylosanthes gracilis et Penniselum purpureum, à col rouge, sont d'un grand intérêt.

Les modalités d'intégration de ces cultures dans l'assolement sont examinées avec indication, pour certaines d'entre elles, des techniques d'exploitation mises en cuvre et des résultats déjà obtenus.
\end{abstract}

Au Tchad, la zone des savanes à grandes graminées couvre la partie sud du territoire et correspond sensiblement à la zone de culture cotonnière, laquelle s'étend de l'isohyète 800-850 mm jusqu'aux confins de la République Centrafricaine où la pluviosité moyenne esł de l'ordre de 1150 à $1.300 \mathrm{~mm}$.

L'agriculture est fondée sur la culture du coton, de l'arachide, du mil et un gros effort de vulgarisation est entrepris, qui vise à l'améliaration des techniques et des moyens de traval, grâce surtout à l'adoption de la culture attelée.

Celle-ci implique donc l'entretien d'un minimum de cheptel qui peut s'élever à deux paires de bœufs par famille. Chacune d'elles étant sensée vivre sur cing ha dont deux de jachère. Il y a donc un problème d'alimentation à résoudre, particulièrement en saison sèche où la vaine pâture ne suffit pas à assurer la nourriture du bétail.

Aussı serait-il souhaitable de pouvoir adopter une culture fourragère qui faciliterait l'entretien

(*) Communication présentée au IX* Congrès internatronal des pâturages, Sao-Paulo (Brésil). 7-20 janvier 1965. du cheptel pendant la saison sèche et assurerait en saison des pluies une production destinée tant à l'affouragement qu'au stockage pour la période de soudure.

L'assolement préconisé par le service de l'Agriculture : coton - mil + arachide - mil + arachide - jachère - jachère, laisse libre deux soles qui pourraient peut-être être remplacées par une praırie artificielle à base de plantes locales ou d'introduction, dont l'intérêt pastoral curait été démontré. C'est pourquoi, ont été entrepris, sur les fermes du service de l'Agriculture du Tchad, des essals de comportement de plantes fourragères, destinés à mettre en évidence les espèces intéressantes, ainsı que des essais d'exploitation par fauchage.

\section{A) ESSAIS DE COMPORTEMENT}

Les critères retenus étaient les suivants :

- résistance d̀ la sécheresse,

- caractères pérennants,

- persistance de l'état vert, et aptitude à la repousse en saison sèche. 
C'est ainsi qu'ont été remarquées les espèces sulvantes:

\section{Graminées :}

- Andropogon gayanus

- Panicum antidotale

- Pennisetum, à collet rouge

- Sorgum almum i

Légumineuses :

- Stylosanthes gracilis, vivace

- Dolichos lablob

- Vigna sinensis

- Dolichos bifiorus

- Pueraria phaseoloides, annuelles, persistants plus ou morns en saison sèche suivant les sols et les variétés.

\section{Cactacées :}

- Le cactus inerme, Opuntia Ficus indica, variété inermis, qui donne de bons résultats en Afrique du Nord et à Madagascar, est ici d'implantation difficile.

En effet, son développement est très lent, ce qui le rend inintéressant dans cette zone.

\section{B) ESSAIS D'EXPLOITATION}

Parmi les espèces citées plus haut, les plus intéressantes d'entre elles ont été mises en exploıtation. Les critères retenus pour juger de leur valeur, étcient :

- l'influence de la périodicité des coupes,

- le nombre de coupes,

- les époques d'intervention,

- le rendement global annuel.

\section{B.1) Stylosanthes gracilis.}

C'est une espèce originaire du Brésil et déjà très utilisée au Congo et en République Centrafricane.

Au Tchad, sa culture est aléatoire au nord de l'isohyète 1.100-1.150 mm. L'influence des précipitations ainsi que de leur répartition est très sensibie, dans cette zone pusque, entre le point d'essai le plus méridional où il tombe annuellement $1.300 \mathrm{~mm}$ de pluie environ, et le point le plus septentrional où la pluviosité est en moyenne de $1.150 \mathrm{~mm}$, les différences de rendement enregistrées pour un même type d'essai varient de
10 d̀ 100 p. 100 en faveur de la ferme la plus arrosée.

De plus, les essais de comportement entrepris sur des stations où les précipitations moyennes sont de l'ordre de $900 \mathrm{~mm}$, ont abouti à un échec dès la deuxième année, la plante n'ayant jamais atteint un grand développement, sans cependant àvoir jamais été fauchée.

\section{B.11) Technique culfurale.}

\section{B.111) Semis.}

$1 /$ peut s'opérer en poquets distants de $50 \mathrm{~cm}$ en tous sens. II paraît n'y avoir aucun intérêt à l'effectuer de façon précoce. En effet, celui du mois de mai, est inférieur à celui du mois d'août. C'est donc vers le milieu de la saison humıde, que l'on obtient la mellieure levée et le développement le plus rapide.

\section{B. 112) Exploitation.}

a) Première onnée.

Une seule coupe semble possible car if faut permettre à la plante de s'installer et d'atteindre un développement suffisant. De plus, Il ne faut opérer qu'à partir d'octobre, car la flambée de croissance intervient en septembre.

Ce sont donc l'aspect de la végétation et les besoins en fourrage, qui décideront finalement de cette première coupe qui peut intervenir d'octobre à décembre.

La quantité d'herbe outenue ne semble pas devoir dépasser les cinq t/ha d'un fourrage de bonne qualité, très appétible, car les tiges sonf encore assez peu développées, donc tendres.

La valeur fourragère se situant en décembre, à $0,15 \cup$. F. et $29 \mathrm{~g}$ de matières protéiques digestibles $/ \mathrm{kg}$, I'on peut donc obtenir, dès la première année, $750 \mathrm{U}$. F. et $145 \mathrm{~kg}$ de matières azotées $/ \mathrm{ha}$, ce qui assure 160 journées de nourriture, en se basant sur le facteur le plus limitant, ici les unités fourragères.

b) Deuxième année.

Le nombre de coupes peut être plus élevé, mais il faut encore respecter la flambée de croissance de la plante qui survient en août.

Trois interventions semblent pouvoir être effectuées, I'une en juin, début juillet, c'est-à-dire au moins un mois avant la flambée de croissance, 
et les autres en septembre-octobre et décembrejanvier.

Le rendement global peut atteindre 25 t/ha d'un fourrage de bonne qualité, puisque fauché trois fois et dont les tiges n'ont pas pris un développement excessif.

La productivité de chaque coupe s'établit dans l'ordre chronologique à :

— 3,7 t/ha a 0,16 U. F. et $32 \mathrm{~g}$ de M.P. D.

$-15 t /$ ha à $0,13 \cup$. F. et 24

- $5,75 \mathrm{t} / \mathrm{ho} \mathrm{à} 0,22 \mathrm{U}$. F. et 30

soit en valeur fourragere :

- 592 U. F. et $118 \mathrm{~kg}$ de M.P.D.

-1.950 U. F. et $360 \mathrm{~kg}$ de M.P. D.

- 1.265 U. F. et $172 \mathrm{~kg}$ de M.P. D.

Au total, I'on semble pouvoir compter sur 3.800 U. F. et $650 \mathrm{~kg}$ de M.P. D. représentant, en se basant sur le facteur limitant, ici encore les U. F., 810 journées de nourriture pour un bovin zébu de travail.

Il faut noter que la troisième coupe peut être retardée, la plante pouvant se conserver verte sur pied. Mals alors, on enregistre une diminution du rapport parties appétées/parties non appétées, par la chute des feuilles comme par une certaine lignification des tiges au fur et à mesure que la saison sèche s'avance. Seules, les extrémités demeurent alors pourvues de porties vertes utilisables.

L'espacement des coupes ou des pacages s'établit donc comme ci-après, dès la deuxième année :

- une coupe en juin,

- une coupe en septembre,

- une coupe en décembre, celle-ci pouvant être retardée, pour permettre le maintien sur pied, d'une certaine réserve de matières vertes, utılısables à une pérıode plus tardıve donc plus critique au point de vue alimentaıre.

Un repos de 3 à 5 mois suit le dernier passage et correspond à la période sèche. Il faudra attendre le retour des pluies ef le mois de juin, pour opérer à nouveau.

\section{B.2) Andropogon gayanus.}

C'est une espèce locale vivace dont il existe de nombreux écotypes adaptés à une sécheresse plus ou moins grande et pouvant croître jusqu'en zone sahélienne.

\section{B.21) Technique culfurole.}

\section{B. 211) Semis.}

II doit être réalisé de préférence en poquets distants de $50 \mathrm{~cm}$ par $50 \mathrm{~cm}$. La levée de cette plante est en effet très irrégulière, et les semis réalisés à la volée, ont toujours donné des résultats décevants.

Quant à la date, il semble là encore que l'on n'ait pas intérêt à semer trop tôt. Le mois de juillet et le début d'août paraissent les plus favorables à la levée.

\section{B. 212) Exploitation.}

a) Première année.

La première coupe ne doit pas être réalisée trop tôt car la plante effectue sa flambée de croissance en septembre. Il faut done attendre le début du mois d'octobre pour opérer.

Le nombre de coupes optimal semble devoir être limité à deux ou trois. En effet, la première intervention est nécessaire pour éviter une montaison rapide qui amènerait un développement excessif des chaumes, au détriment des parties appétibles. Elle paraît devoir être réalisée en octobre.

Quant à la deuxième coupe : on peut l'effectuer fin décembre. Toutefois, cette date peut être retardée si l'on désıre conserver sur pied du fourrage vert.

II faut cependant signaler qu'en février-mars, les touffes d'Andropogon goyanus coupées, émettent un certain nombre de repousses atteignant une trentaine de centimètres de hauteur.

L'on n'a donc pas intérêt à retarder trop celle deuxième coupe.

Latroisième intervention, facultative, peut avoir lieu selon l'importance des repousses et seton les besoins, en mars.

Le rendement global n'excède pas 5 t/ha réparties comme suit :

- 3,7 t pour la première coupe,

- 1,3 t pour la deuxième coupe.

Les résuitats de la troisıème coupe, aléatoires, la première année, en raison de l'installation de la plante sur le terrain, seront négligés.

La valeur fourragère escomptée est de :

- 0,15 U. F. et $4,5 \mathrm{~g}$ de M. P. D. $\mathrm{kg}$ pour la première coupe, 
- 0,10 U. F. et $1,5 \mathrm{~g}$ de M. P. D. $/ \mathrm{kg}$ pour la deuxième coupe, ce qui correspond pour 1 ha à :

- 555 U. F. et $16,5 \mathrm{~kg}$ de M. P. D. dans le premier cas ;

- 130 U. F. et $2 \mathrm{~kg}$ de M.P. D. dans le second cas,

Au total, I'on peut compter sur $685 \cup$. F. et $18,5 \mathrm{~kg}$ de M.P. D., représentant 69 journées de nourriture, pour un bovin de travail, en tenant compte du facteur limitant, icı les matières protéiques digestibles.

b) Deuxième année.

Bien que les expériences soient en cours actuellement, Il semble que l'on puisse normalement effectuer trois coupes, la plus importante étant celle de septembre, la flambée de croissance intervenant en aout.

La production pourrait atteindre 30 à 40 t/ha, d'un fourrage dont la richesse moyenne est de $0,15 \cup$. F. et $4,5 \mathrm{~g}$ de M.P. D. $/ \mathrm{kg}$.

\section{C) INTÉGRATION \\ DES CULTURES FOURRAGËES DANS L'ASSOLEMENT}

L'assolement préconisé par le service de I'Agriculture du Tchad, prévoit trols années de cultures suivies de deux années de jachère.

Il pourrait être tentant de remplacer ces dernières par des cultures fourragères, mais le délai imparti pour leur installation, semble trop court. En effet, pour retirer le maximum d'une prairie artificielle avant que ses rendements ne baissent, il faut quatre ou cinq années.

C'est pourquoi plusieurs solutions peuvent être proposées suivant que l'on voudra ou non, intégrer ces pâturages artificiels à l'assolement.

L'on pourra ainsı envisager, soit la prolongation de la durée de la jachère, soit la mise hors circuit temporaire d'une sole supplémentaire qui ne serait remise en culture que tous les cing ans, soif enfin l'instailation sur une parcelle de dimensions suffisantes, exclusivement réservée à cet effet.

La deuxième solution parâ̂t la plus normale car elle permet de faire bénéficier les cultures tous les cinq ans - et en particulier la tête d'assolement, c'est-à-dire le coton - d'un sol enrichi en azote par la légumineuse et en matières organiques grâce d̀ l'enfouissement de la dernière repousse préalablement pâturée.

Pour fournir l'essentiel de la nourriture indispensable aux quatre boufs de travail de notre famille type d'agriculteurs, Il faut un hectare de pâturages artificiels en pleine production, c'està-dire ayant au moins une année d'âge.

Le semis de 0,5 ha de stylosanthes gracllis et de 0,5 ha d'Andropogon gayanus, ou éventuellement d'un mélange des deux espèces, peut permettre d'obtenir 4.900 U. F. et $415 \mathrm{~kg}$ de M. P. D., ce qui semble suffisant pour assurer la couverture des besoins de ce cheptel, pendant 9 mols, évalués à 5.130 U. F. et $297 \mathrm{~kg}$ de M. P. D. II faut ajouter à cela 273 U. F. et $45 \mathrm{~kg}$ de M.P. D. provenant des graines de coton de la production annuelle et en plus des fanes d'arachides, des tiges et feuilles de mil séchées sur pıed, ainsı que du pâturage de brousse de qualıté médiocre. En juillet, août et septembre, la nourriture peut être fournie par les parcours de brousse ou les. jachères naturelles où les jeunes pousses d'herbe constituent un aliment idéal.

On aura donc seulement à prolonger l'assolement d'une année c'est-à-dıre, à augmenter les surfaces cultivées, de 1 ha, ce qui porterait la surface exploitée à 6 ha. Cette parcelle ne devrait être remise en culture que tous les 6 ans et remplacée au préalable, l'année avant son retournement, par f'ensemencement d'une autre parcelle destinée à la jachère.

\section{D) UTILISATION \\ DE LA PRAIRIE ARTIFICIELLE}

On peut la concevoir sous plusieurs formes, la plus simple étant le pacage. Mais celui-ci peut aboutır, en saison des pluies, à un gaspillage de fourrages, l'herbe étant alors très abondante. De plus, les parcours de brousse offrent des possibilités non négligeables à cette époque. C'est pourquoi il faut envisager des techniques permettant le stockage du fourrage artificiel. pour les périodes de soudure.

C'est ainsı que l'on peut utiliser le fauchage soit en vue de fanage, soit pour la confection d'ensilages.

La première méthode est de réalisation difficile en saison des pluies, alors que la seconde, 
déjà utilisée sur les fermes de l'Agriculture du Tchad, donne de bons résultats.

Nous retiendrons cette dernière qui permettrait de conserver le produit de la première et surtout de la seconde coupe pour la saison sèche.

Le fauchage en vue de la distribution dans l'enclas de parcage peut être envisagé pour la coupe de décembre-janvier, afin de limiter les pertes occasionnées par le piétinement du bétail. lors du pacage, ef correspond à une ration de supplémentation destinée à pallier aux insuffi- sances du pâturage de brousse de saison sèche.

\section{E) CONCLUSION}

Les expériences entreprises sont encore trop peu nombreuses pour qu'il soit possible d'en tirer des enseignements définitifs. Ce n'est que d'ici quelques années que l'on pourra disposer de données suffisantes pour tenter la vuigarisation de techniques valables et utilisables par tous les agriculteurs.

\section{SUMMARY}

The artificial pasture-lands in savannah zone with pronounced dry season

After a brief review on the climatic conditions in the Chad republic, the author explains the results obtained in the introduction of fodder plants.

The inermous Cactus gives disappointing results ; Panicum antidotale, Andropogon gayanus and Stylosanthes gracilis, Pennisetum purpureum with a red collar, are on the other hand interesting.

The growing technics of integration in the local rotations are indicated and the author appreciates the productivity and the fodder value expected and the delay to respect.

\section{RESUMEN}

\section{Los pasios artificiales en zona de sábana \\ de estación seca importante}

Después de un breve resumen de ias condiciones climátıcas de la república del Tchad, el autore expone los resultados alli obtenidos con la introducción de plantas forrajeras.

El Cactus inerme da resuliados decepcionantes; por el contrario los cultivos de Panicum antidotale, Andropagon gayanus, Stylosanthes gracilis y Penniselum purpureum, con cuello rojo, san altamenle interesantes.

Las técnicas de cultivo de integración en los campos locales son indicadas, el autor evalua las perdidas de productividad y vaior forrajera de las plantas, y marca los tiempos de reposo a respeciar. 